\title{
Ética pública y deber de abstención en la actuación administrativa
}

\section{Public ethics and duty of abstention in administrative action}

\section{JOSÉ LUIS MARTÍNEZ LÓPEZ-MUÑIZ”}

Resumen: La ética debe impulsar, sostener, inspirar y complementar al Derecho, aunque lo exigible al poder público, bajo el Estado social y democrático de Derecho, es su plena sumisión a este. El deber de abstención de los servidores públicos cuando se encuentran en las situaciones que la ley determine por comportar riesgo de parcialidad o de servicio a algún interés particular y no a los fines públicos es solo una medida precautoria, que busca la mejor garantía de la efectiva sumisión de toda actuación del poder público al Derecho, así como también favorecer la confianza del ciudadano en las autoridades y en los empleados públicos. Esto ha sido construido en el siglo XX, a partir de la figura de la recusación, de gran arraigo histórico en el ámbito judicial, la cual ha pasado a ser incluida en la configuración institucional. La comparación de su regulación en el ámbito administrativo en los derechos peruano y español favorece un análisis de las particularidades de su régimen jurídico.

Palabras clave: Ética pública - Estado de Derecho - administración pública acto administrativo - procedimiento administrativo - recusación abstención

\begin{abstract}
Ethics should promote, sustain, inspire and complement the Law, although, under social and democratic Rule of Law, it is required the entire submission of Public Administration to Law. Public employee's duty of abstention, when they find themselves in situations determined by law as under the risk of partiality or service to particular interests and not to public purposes, is only a precautionary measure that search for the best guarantee of effective submission to Law of all public power proceedings and promote citizen's trust in their authorities and public employees. Duty of abstention was built in XX century from the legal concept of recusation which is historically deep-rooted in legal field, and it is included in institutional setting. Comparison of regulations between Peruvian and Spanish Law in the administrative field promote an analysis of legal system particularities.
\end{abstract}

Key words: Public ethics - Rule of Law - Public Administration - Administrative action - Administrative Procedure - Recusation - Abstention

* Es catedrático de Derecho Administrativo de la Universidad de Valladolid (España). Correo electrónico: marlomu@der.uva.es. 
SUMARIO: I. SOBRE LA LLAMADA ÉTICA PÚBLICA. - II. EL DEBER DE ABSTENCIÓN EN SU GESTACIÓN Y SUS PORQUÉS HISTÓRICOS. - III. CARÁCTER INCIDENTAL DEL PROCEDIMIENTO DE ABSTENCIÓN Y RECUSACIÓN. - IV. EL DEBER DE ABSTENCIÓN DE LAS AUTORIDADES ADMINISTRATIVAS EN LA LEY PERUANA DE PROCEDIMIENTO ADMINISTRATIVO GENERAL DE 2001.

\section{SOBRE LA LLAMADA ÉTICA PÚBLICA}

$\mathrm{Si}$, a efectos de pulsar qué se está entendiendo hoy por ética pública, acudimos a uno de los conocidos buscadores de Internet, esta nos aparece de inmediato definida como «ética aplicada y puesta en práctica en los asuntos de gobierno» o «ética aplicada en los servidores públicos, entendiendo por éstos aquéllas personas que ocupan un cargo público ya sea por elección, oposición u otro medio, y que tienen una responsabilidad ante el Estado [...] que se traducen en actos concretos orientados hacia el interés común y/o de la ciudadanía. La ética pública se refiere entonces a los actos humanos en tanto que son realizados por gobernantes y funcionarios públicos en el cumplimiento del deber» ${ }^{1}$.

Se tiene también generalizada, por lo contrario, a la denominada corrupción en la actuación de los poderes públicos².

En España, Jaime Rodríguez-Arana, que ha publicado varios libros al respecto en los últimos años, viene a identificar la ética pública con la ética de la función pública, como «ciencia de la actuación de los funcionarios orientados al servicio público, al servicio de los ciudadanos, al compromiso con el bienestar general de la gente», o «la ciencia del servicio público en orden a la consecución del bien común, del bien de todos haciendo, o facilitando el bien de cada uno de los miembros de la sociedad $»^{3}$ y considera igualmente como «lugar común afirmar que las conductas antiéticas en el servicio público responden ordinariamente y con carácter general al nombre de corrupción», cuyo «fenómeno consiste en la desnaturalización del poder público que se opera, en lugar de al servicio de los demás, en provecho de quien lo ejerce», si bien inmediatamente, al ampliar y difuminar la significación de esta noción — que es ciertamente muy indeterminada y depende de contextos- dirá que, sin embargo, «la »corrupción»—que pone ahora así, entre comillas— más

1 DiEGO, Óscar. «Introducción a la ética pública». En http://www.dilemata.net/index.php/Etica-publicay-buen-gobierno/introducci-la-ica-pca.html (27 de febrero de 2008). Óscar Diego Bautista es autor del libro Ética pública y buen gobierno (fundamentos, estado de la cuestión y valores para el servicio público). Toluca: Instituto de Administración Pública del Estado de México, A.C., 2009, donde se encuentran más desarrollados esos mismos conceptos, y que se encuentra en la siguiente dirección electrónica: http://eprints.ucm.es/9829/1/eticapublica.pdf.

2 Véase: CANALES ALIENDE, José Manuel. «Algunas reflexiones sobre la ética pública». VII Congreso Internacional del CLAD sobre la reforma del Estado y de la administración pública. Lisboa, Portugal, 8-11 de octubre de 2002. El autor recuerda significativamente que «en algunos países como en U.S.A., con motivo del Watergate en 1978 va a tener un lugar prioritario desde entonces".

3 Rodríguez-Arana, Jaime. La dimensión ética. Madrid: Dykinson, 2001, p. 30. 
grave que acecha a la administración es el ambiente de incompetencia o mediocridad de quien no es consciente del elevado valor que tiene el servicio público, cualquiera que sea el puesto que se ocupe en la maquinaria administrativa ${ }^{4}$. Fernando Sainz Moreno - como ha recordado José Luis Carro- ha llegado a condensar la ética positiva exigible a los servidores públicos en el trabajo bien hecho 5 .

La ética es, a nuestro entender, la dimensión normativa de la ontología antropológica propia del ser humano en su integridad ${ }^{6}$, con su inescindible doble dimensión personal como individuo y miembro solidario de la sociedad, como ser compuesto de materia y espíritu — de razón, por tanto-, determinado por una naturaleza común recibida y permanente, que incluye en todo caso determinados procesos y condicionamientos biológicos, psicológicos y ontológicos, pero, a la vez $-\mathrm{y}$ dentro de las limitaciones que todo esto comporta-, dueño y responsable de su conducta por la autodeterminación de su libertad, en orden a su desarrollo, a su perfeccionamiento personal y al de la sociedad actual y del futuro, mediante el ejercicio de sus potencialidades, y el uso y aprovechamiento racional del universo material que le rodea, dentro de la amplia gama de alternativas que la misma naturaleza hace posible.

Es la ética la que impera criterios de ordenación racional de la conducta de cada ser humano a sus fines, determinando así lo bueno, lo menos bueno y lo malo en el orden moral que abarca la vida interior y no solo la exterior de cada persona. La conciencia de cada uno debe impregnarse de correcto sentido ético y dirigir así toda la conducta -interior y exterior - certeramente al bien. De que así suceda dependerá el destino de cada cual y también el de la sociedad, que no tiene más entidad real que la relacional en cuanto formada por el conjunto de las personas humanas, y depende, por tanto, del comportamiento de estas, aunque el de algunas tenga más capacidad de incidencia, condicionamiento y arrastre que el de otras.

El Derecho no puede desvincularse de la ética, pero, en sentido estricto, es realidad relacional distinta: se refiere solo a relaciones interpersonales que comportan la exigibilidad de determinadas conductas activas o pasivas de unos con respectos a otros, por razón de determinadas «cosas» distribuidas entre ellos —entendidas estas en su más amplio sentido,

4 Ibíd., pp. 31-32.

5 CARRo FernÁNDEZ-Valmayor, José Luis. «Ética pública y normativa administrativa». Revista de Administración Pública, número 181, 2010, p. 13.

6 La ética, por tanto, y también la pública, tiene una fundamentación metafísica. Sobre la base del relativismo imperante en algunos medios culturales, basado comúnmente en teorías del conocimiento que niegan la capacidad de este de acceder al ser de las cosas y en particular del ser humano, se ha tratado de construir una denomina ética pública surgida de supuestos consensos sociales generalizados, cuya fragilidad — llena de graves riesgos para el ser humano- deriva de la ausencia del firme asidero que solo las verdaderas exigencias de la realidad del ser puede procurar.

ÉTICA PÚBLICA

Y DEBER DE

ABSTENCIÓN EN

LA ACTUACIÓN

ADMINISTRATIVA

PUBLIC ETHICS

AND DUTY OF

ABSTENTION IN

ADMINISTRATIVE

ACTION 
donde se incluyen la vida y los bienes también inmateriales del ser humano- que la sociedad debe garantizar.

El Derecho ha de basarse en la ética e incluirse en ella, pero contiene muchos elementos que solo son asumidos por la ética a partir de su legítima juridificación, por cuanto representan en sí mismos una opción entre otras muchas también éticamente legítimas, aunque pasen a ser concreción de deberes éticos una vez que pasan a convertirse en parte del Derecho. La ética, en su dimensión social, tiene así en el Derecho, debidamente establecido, un instrumento muy importante de concreción, aunque no se agote en él, ni deba pretenderse. Se ha dicho más de una vez que el Derecho debe asegurar un mínimum ético. Aunque sea muy amplio, no todo lo éticamente debido en las relaciones interpersonales debe ser conformado como Derecho, con la consiguiente exigibilidad coercible.

De lo que estamos hablando entonces cuando adjetivamos la ética como pública puede ser, en efecto, discutible, pues puede referirse a los criterios e imperativos de la ética sobre cualesquier conducta humana que trascienda el ámbito de la llamada privacidad — propio de las relaciones familiares y domésticas, de las relaciones de amistad, del ámbito interno incluso de organizaciones voluntarias y libres en cuanto no afecte a terceros- $\mathrm{o}$, más restrictivamente, puede hacer referencia a las que tienen lugar en las relaciones que tienen en alguna de sus partes a algún poder público, o, incluso, y aún más limitadamente —como hemos visto anteriormente-, solo a aquellas conductas de quienes desempeñan cargos o empleos públicos.

En cualquier caso, indudablemente forma parte de la ética pública la que rige en el plano propio la actuación de personas humanas como administración pública o poder judicial, o, en fin, la que rige como legisladores y como cualquier otra manifestación del poder público, con el requisito, desde luego, de que comience en una democracia, y en los ciudadanos convocados para ejercer las supremas potestades.

Resulta, sin embargo, que, bajo los principios del Estado de Derecho hoy imperantes, el poder público — salvo el supremo y soberano, residenciado en el pueblo- está sometido positivamente al ordenamiento jurídico, de modo que solo puede llevar a cabo lo que este explícitamente —y, bajo ciertos límites, implícitamente- - le permite, aquello que, en su aplicación, comporta una especial densidad de sumisión por parte de los poderes ejecutivo y judicial. Este último es el que más estrictamente está sometido al imperio de la ley, pero también la administración pública se encuentra plenamente sometida a la ley y al Derecho, como viene a decir el artículo 103 de la Constitución española. Podríamos decir que lo que importa es que jueces y administradores públicos o gobernantes —en tanto nivel superior de las correspondientes administraciones- 
cumplan la ley, y se acomoden en su conducta como tales al ordenamiento jurídico y al Derecho. La ética tendrá para ellos —y para el impulso interior que facilite y sostenga eficazmente su buen hacer-, como personas, la mayor trascendencia, desde luego, pero lo que la sociedad puede exigirles es que actúen conforme a Derecho, lo que no quita que, como ha quedado apuntado, sea importantísimo que ese Derecho, a su vez, se base y refleje en una ética correcta, y respete y cumpla sus requerimientos, que están certeramente fundados en el ser del hombre, de la sociedad, del poder público y de las cosas en general ${ }^{7}$. Pero es claro que esta dimensión ética, con toda su trascendencia, se encuentra en un plano distinto del Derecho, que es de lo que se ocupan las leyes, por más que, ocasionalmente, alguna importante ley pueda remitir al límite que supone la moral o las buenas costumbres, tal y como ocurre en el Derecho español, en materia de contratos privados (artículos 1255 y 1275 del Código Civil) o de vigencia de las costumbres como fuente de Derecho (artículo 1.3 del Código Civil). La moral ha sido considerada tradicionalmente un límite general, al menos negativo - propiamente jurídico-, en el alcance de los derechos y libertades y así se proclama en el artículo 29.2 de la Declaración Universal de Derechos Humanos de 1948 y se concreta, más específicamente, con respecto a algunos en los diversos textos normativos internacionales que de ella dependen ${ }^{8}$. Pero, en realidad, la dimensión jurídica que entonces alcanza la moral o la ética no deja de tener unos alcances limitados y no fáciles de determinar?.

En la actuación de la administración pública —y del Gobierno, que no es sino su escalón directivo- su vinculación positiva al ordenamiento jurídico comporta, sin embargo, las más de las veces, espacios más o menos amplios de discrecionalidad o márgenes de apreciación de los presupuestos de la necesidad o posibilidad de actuar, del momento de hacerlo y de cómo hacerlo. Solo en algunas manifestaciones de su obrar está todo completamente predeterminado por las normas aplicables, de modo que pueda hablarse de actos o actuaciones «reglados» y en términos tan claramente determinados que no dejen margen alguno para la interpretación. Están, con todo, los principios generales del Derecho que, como parte muy importante del Derecho mismo, no dejan de marcar límites y exigencias que reducen considerablemente los márgenes

7 CARRO FERnÁNDEZ-VAlmayoR, José Luis. Ob. cit., pp. 15 y siguientes. Se refiere a los diversos valores y principios de sustancia ética que estarían positivizados en la Constitución española y luego desarrollados en la legislación administrativa.

8 Como el artículo 18.3 del Pacto Internacional de derechos civiles y políticos de 1966, que además se refiere a la moral pública como límite de la libertad de manifestar la propia religión o las propias creencias. Igualmente, véase el artículo 19.3b del mismo pacto, en cuanto a la libertad de expresión, o el 21, con respecto al derecho de reunión, y el 22, en cuanto a la libertad de asociación. También se refiere a su moral el artículo 10.3 del mismo Pacto Internacional de derechos económicos, sociales y culturales, para proteger a los niños y adolescentes, frente a su empleo en trabajos nocivos, etcétera. Las legislaciones nacionales siguen conteniendo disposiciones o aplicando criterios similares.

9 Véase nuestro estudio «La moralidad pública como límite de las libertades públicas». Revista de Derecho Administrativo, año 6, volúmenes 15-16, enero-agosto 1994, pp. 109-125, Buenos Aires.

ÉTICA PÚBLICA

Y DEBER DE

ABSTENCIÓN EN

LAACTUACIÓN

ADMINISTRATIVA

PUBLIC ETHICS

AND DUTY OF

ABSTENTION IN

ADMINISTRATIVE

ACTION 
de la opción admisible, de modo que nunca puede hablarse de algo que tenga que ver propiamente con la libertad, la libre elección o la autonomía de la voluntad cuando de entidades y organismos públicos se $\operatorname{trata}^{10}$.

Los imperativos éticos podrían pasar, de todos modos, a desempeñar aquí — en esos márgenes de la discrecionalidad o de apreciación reconocidos al tratarse de la administración - un protagonismo más directo, precisamente por falta de la íntegra predeterminación propiamente jurídica de la acción. Todo lo mencionado es cierto, sin embargo, en el orden de las exigibilidades donde no llega el Derecho, en esos márgenes de opción del poder gubernativo y administrativo — como de modo aún más amplio ocurre en el ámbito del Poder Legislativo-, están estos sometidos a los imperativos sustantivos y de garantía de la política, que es algo muy relacionado con la ética y con el Derecho, pero distinto de una y de otro, y cuya efectividad sí que es garantizada por el Derecho. Será la responsabilidad política - requerida, encauzada y garantizada por el Derecho- la que juegue entonces donde no llegue la responsabilidad propiamente jurídica, por más que los supuestos de aquella, como los de esta, deban estar impregnados de ética.

En suma, y para no alargar ya más estas reflexiones, será muy conveniente - si es que no es imprescindible - que cuantas personas se ocupen de la cosa pública estén hondamente penetradas de una íntegra y acertada ética pública, que es quizás el principal bagaje para dar efectividad al Derecho y al Estado de Derecho, así como para orientar rectamente la política que este encauce y plasme. Pero la misma ética demanda un correcto y riguroso funcionamiento del Derecho, con todas sus consecuencias, incluido el que sirve a garantizar la responsabilidad política. Y en el orden de las exigibilidades relevantes socialmente, hay que atenerse, en suma, al Derecho, y también a la política que el propio Derecho hace posible y garantiza. Las responsabilidades éticas, además, son de muy difícil evaluación por implicar siempre — si se las comprende en su plenitud-a la interioridad de la conciencia. En el plano del Derecho — y más aún de la política-, aun cuando pueda tener relevancia a algunos efectos la intención y la voluntad interna $-\mathrm{y}$ siempre que sea susceptible si quiera de acreditación suficientemente indiciaria externa-, nos atenemos a lo externo y objetivo principalmente.

10 Aunque algunas normas sigan hablando por inexplicable inercia y de modo contradictorio de una libertad de pactos de la administración pública en sus contratos (artículo 25 de la española Ley 30/2007, del 30 de octubre, sobre contratos del sector público). Véase: BACA ONETO, Víctor S. La invalidez de los contratos públicos. Navarra: Thomson-Civitas, 2006, pp. 117-118, nota 337. 


\section{EL DEBER DE ABSTENCIÓN EN SU GESTACIÓN Y SUS PORQUÉS HISTÓRICOS}

Pues bien, desde antiguos tiempos el Derecho ha detectado la relevancia de establecer previsiones que dificulten la injusticia en la toma de decisiones del poder público, por razones de parcialidad o de intereses particulares de quien las adopta, de quien las prepara o de quien puede contribuir de modo determinante a ellas desde las propias estructuras de tal poder público, con lo que se quiebra la legítima confianza de los súbditos, de los ciudadanos, de las partes de un proceso o de los administrados en el servicio de aquel frente la verdad objetiva, a la justicia y al Derecho.

Dada la usual mezcla y confusión que, en una u otra medida, se dio históricamente entre las funciones administrativas y judiciales —e incluso con las normativas que hoy encuadraríamos como legislativas- es fácil comprender que tales previsiones emergieran en el ámbito judicial, ya que fueron el Derecho penal y el Derecho procesal civil y penal los que establecieron progresivamente, a lo largo de los siglos, las garantías efectivas de las personas en cuanto a la actuación del poder público.

Lo que surgió primero en este orden fue probablemente la figura de la recusación, de la que habla como una de las posibles excepciones dilatorias De Dou y Bassols en su valiosa obra Instituciones del Derecho público general de España (con noticia del particular de Cataluña y de las principales reglas de gobierno en cualquier Estado), publicada en los años iniciales del siglo XIX, como auténtico albacea del antiguo régimen. Citamos de ella lo siguiente ${ }^{11}$ :

Es cosa muy dura, y de temibles consecuencias el haber de ser el reo juzgado por un enemigo suyo, ó por personas interesadas en condenarle con las poderosas pasiones de interés, amor, odio, avaricia u otras semejantes: también es duro, aunque no tanto, el haber de ser juzgado por magistrado, de quien desconfíe o tenga rezelo la parte, aunque no pueda justificar causa particular y legal para recusarle $[\ldots]$

En el día tenemos en esta parte [...] que por derecho de Castilla los magistrados ordinarios pueden ser recusados voluntaria y libremente sin justificación de causa, por no removérseles del todo del conocimiento, obligándoles solamente á acompañarse con otro [...]

Para recusar á los ministros de audiencias y consejos se necesita de causa (ley 1 y 2 , tit. 10, li. 2, Rec.) [...] Constando [...] que con legítima causa no hay juez que no pueda ser recusado ${ }^{12}$.

No se habla en cambio, en una obra tan omnicomprensiva, de un deber de abstención que parece haberse ido construyendo precisamente

ÉTICA PÚBLICA

Y DEBER DE

ABSTENCIÓN EN

LA ACTUACIÓN

ADMINISTRATIVA

PUBLIC ETHICS

AND DUTY OF

ABSTENTION IN

ADMINISTRATIVE

ACTION 
a partir de la institución de la recusación, aunque la exceda con mucho. En España, las grandes leyes procesales adoptadas en 1881 (Ley de Enjuiciamiento Civil) y en 1882 (Ley de Enjuiciamiento Criminal), vigentes prácticamente hasta nuestros días ${ }^{13}$, establecerían ya unos deberes de abstención de jueces, magistrados y asesores (artículos 190 y 55, respectivamente), pero, precisamente, en el marco de regulación de la recusación.

Todavía a mediados del siglo XIX, aquella gran obra de incipiente Derecho administrativo que fue el Derecho administrativo español, de Manuel Colmeiro, también trata solo de recusación y, además, lo hace solo someramente a propósito de la actuación de la jurisdicción contenciosoadministrativa - establecida pocos años antes en España siguiendo de cerca el modelo francés de la época-, y no de la administración pública como tal ${ }^{14}$.

La traslación de la recusación al ámbito propio de la actuación de la administración pública y, por tanto, del procedimiento administrativo, no se producirá, según parece, hasta muy avanzado el siglo XX, dándose además el paso de configurar a la vez — sobre la base indudablemente de lo ya aplicado en el Derecho judicial — un deber de abstención superior e independiente con respecto a la recusación, que englobaría esta institución como una de sus implicaciones, de modo que lo principal y primario pasaría a ser, incluso en su presentación formal en la ley, el deber de abstención de la cual, justamente, una de sus secuelas sería la recusación, con lo que se cambiaba así el modelo que aún entonces ofrecía la legislación procesal ${ }^{15}$. Por lo que se refiere a España, no hay aún rastro de nada de esto en la obra doctrinal más difundida en la restauración, en las últimas décadas del siglo XIX y a principios del siglo $\mathrm{XX}^{16}$, ni en la primera ley sobre el procedimiento administrativo, ciertamente pionera en el panorama comparado, sancionada el 19 de octubre de 1889 y que contaba aún con las limitaciones propias de la época.

Sería la memorable Ley de Procedimiento Administrativo de 1958 la que, por vez primera en España, y desde luego con su generalidad de aplicación a toda actuación de cualquier administración pública, dedicó una regulación específica a la abstención y a la recusación en este ámbito en sus artículos 20 y 21 respectivamente, que componían el capítulo IV del título primero, dedicado a los órganos administrativos.

13 lbíd., pp. 84-86. Sigue esta obra analizando las causas «aprobadas para recusar al juez».

14 Tomo II, librerías de don Ángel Calleja (Madrid y Santiago), y casa de los señores Calleja, Ojea y Cía. (Lima), 1850, pp. 258 y siguientes.

15 Sería a partir de la Ley Orgánica del Poder Judicial, 6/1985, del 1 de julio (artículos 217 y siguientes), cuando se recibiría formalmente el modelo que se abrió camino primero en el ámbito administrativo, y ahora ya explícitamente incorporado a la nueva Ley de Enjuiciamiento Civil $1 / 2000$, artículos 99 y siguientes.

16 SANTAMARÍA DE PAREDES, Vicente. Curso de Derecho administrativo (según sus principios generales y la legislación actual de España). Sexta edición. Madrid: Ricardo Fé, 1903. 
Esos preceptos han tenido influencia en toda la América hispanohablante en donde se ha honrado la ley, y han pasado a ser, décadas más tarde, con idéntica estructura y pocos retoques, los artículos 28 y 29 de la vigente ley española 30/1992, de régimen jurídico de las administraciones públicas y del procedimiento administrativo común, en la que constituyen también un capítulo específico -el tercero del título segundo-, asimismo dedicado a los órganos de las administraciones públicas.

Una vez explicitado el deber de abstención en el ámbito administrativo, la legislación de funcionarios lo incorporaría de manera explícita al estatuto funcionarial, tras años en los que solo aparecía en la normativa reglamentaria de disciplina funcionarial que tipificó como falta grave su incumplimiento. Aún la Ley de Funcionarios Civiles del Estado de 1964 no incluyó de manera expresa el deber de abstención entre los deberes de los funcionarios. Habilitado por esta ley en unos términos que ya no serían posibles bajo el más severo principio de legalidad sobre cualesquiera sanciones administrativas, establecido por el artículo 25 de la Constitución de 1978, fue el decreto 2088/1969, del 16 de agosto, el que, al establecer un nuevo reglamento disciplinario de los funcionarios civiles del Estado, tipificó por vez primera, bajo la letra $\mathrm{m}$ de su artículo 7, como falta grave «la intervención en un procedimiento administrativo cuando se dé alguna de las causas de abstención legalmente señaladas» ${ }^{17}$. De ahí pasaría tal cual a la letra g también del artículo 7 del vigente reglamento de régimen disciplinario de los funcionarios de la administración del Estado, aprobado por real decreto 33/1986 del 10 de enero, e igualmente sin la necesaria cobertura legislativa que, en punto a tipificación de infracciones y sanciones, ya requería entonces la Constitución, sin que hasta el día de hoy se haya aún satisfecho esta exigencia - lo que, naturalmente cuestiona su validez- ${ }^{18}$. Ha sido el Estatuto Básico del Empleado Público (ley 7/2007), del 12 de abril, el que, finalmente - aun sin resolver, sin embargo, el serio problema indicado de falta de cobertura legislativa de las faltas graves (y leves) del Reglamento disciplinario-, explicitó que los empleados públicos, y no solo los funcionarios propiamente dichos - mas sin inclusión de los cargos de designación política-, «se abstendrán en aquellos asuntos en los que tengan un interés personal». En el apartado 5 del artículo 53 se hace un listado en el que aparecen hasta doce distintos tipos de deberes u obligaciones que responderían a lo que expresamente se denomina

17 Es significativo que una obra tan completa y de tan elevada talla intelectual como el tomo III, volumen II, del Tratado de Derecho administrativo, de José Antonio García-Trevijano Fos no dedique prácticamente atención al tema (pp. 711-725 y 989).

18 Así se deduce de lo afirmado, con toda razón, por la sentencia del Tribunal Constitucional 99/1987, del 11 de junio, aunque este tribunal no haya tenido aún ocasión de pronunciarse sobre el real decreto 33/1986. Solo diversas leyes de comunidades autónomas para sus funcionarios, o algunas leyes estatales especiales para algunos funcionarios estatales, como las leyes orgánicas que regulan el régimen disciplinario de la policía, de la guardia civil o —ya en el ámbito judicial— de los jueces y magistrados han resuelto este problema. (Véase: SÁNCHEZ MORÓN, Miguel. Derecho de la función pública. Sexta edición. Madrid: Tecnos, 2011, p. 312. 
«principios éticos», distinguiéndolos —no hay manera de saber con qué criterio en realidad - de los englobados en el artículo 54, en los que esa ley decide llamar "principios de conducta», unos y otros constitutivos de lo que el artículo 52 denomina, con no escasa retórica, como puede observarse, Código de Conducta de los Empleados Públicos ${ }^{19}$. Pero, además, acogiendo una tendencia actual a un trato aún más exigente, que ofrezca mayor transparencia y garantías frente a posibles reales conflictos de intereses, el citado artículo 53.5 amplía expresamente el deber de abstención del empleado público a «toda actividad privada o interés que pueda suponer un riesgo de plantear conflictos de intereses con su puesto público $»^{20}$. El deber de abstención queda, en todo caso, altamente indeterminado, aunque la lógica jurídica obliga a entender que algún valor habrá que dar, a estos efectos, a las concreciones contenidas en la ley 30/1992 si no se quiere incurrir en una falta de seguridad jurídica poco o nada aceptable ${ }^{21}$.

En cualquier caso, la asunción del deber de abstención en los casos de interés personal de la autoridad o del empleado público que deba actuar como tal, y particularmente cuando concurran las causas que la ley determina, se fundamenta en una razón de precaución. Se trata de evitar que, en todo caso, quien tenga unas determinadas relaciones personales con los interesados, en asunto sometido a conocimiento y decisión de la administración, o con las implicaciones del asunto mismo que puedan comportar riesgo para la imparcialidad en su actuación, intervenga en él de cualquier modo relevante como órgano de la administración. No es descartable, desde luego, que, aun teniendo esas relaciones, se sirvan de hecho objetivamente y con la mayor imparcialidad y pulcritud los fines públicos, con pleno sometimiento al ordenamiento establecido y con toda justicia, como exigen en el Derecho español los artículos 103.1 y 103.3, y 106.1 de la Constitución. Y, si lo finalmente decidido o la actuación administrativa de que se trate incurren en desigualdad indebida de trato, en favoritismo o en desviación de poder, será ilegal y anulable o nulo en razón de esas infracciones del ordenamiento, con independencia del incumplimiento

19 Carro Fernández-Valmayor, José Luis. Ob. cit., pp. 21. El autor plantea el problema de su eficacia jurídica en materia sancionatoria, con corolarios de no poca trascendencia sobre la eventual inconstitucionalidad de algunos aspectos de esa regulación.

20 Hace notar la evidente ampliación que esto comporta, y propone sucintamente reforzar la regulación (Véase: IRURZUN MONTERO, Fernando. «Ética y responsabilidad en la administración pública». En Documentación Administrativa, números 286-287, 2010, pp. 104-105.

21 Aunque no podremos ocuparnos de ello, en estos últimos años se han aprobado también en España la ley $5 / 2006$, del 10 de abril, sobre regulación de los conflictos de intereses de los miembros del gobierno y de los altos cargos de la administración general del Estado, así como el llamado «Código de buen Gobierno de los miembros del Gobierno y de los altos cargos de la Administración General del Estado", del 18 de febrero de 2005, hecho público por orden del ministerio de administraciones públicas APU/516/2005, del 3 de marzo. Para más información, véase: GARCíA MEXíA, Pablo. «Ética, gobierno y administración en la España contemporánea». En Jaime Rodríguez Arana (director). EI derecho a una buena administración pública. Salamanca: Junta de Castilla y León, 2008, pp. 113 y siguientes, particularmente p. 121. También véase: CARRO FERNÁNDEZ-VALMAYOR, José Luis. Ob. cit., pp. 18 y siguientes, especialmente pp. 26 y siguientes. 
del deber de abstención, por más que, si se produjo verdaderamente, no deje de comportar indicios que pueden tener significativos efectos probatorios.

Pero el ordenamiento ha considerado preferible evitar el riesgo comprensible que entrañan las relaciones de presumible interés que causan el deber de abstención. Es lo mismo que ocurre con otras medidas solo precautorias análogas, como la imposición de un sistema de incompatibilidades en el ejercicio de cargos o empleos públicos ${ }^{22} \mathrm{O}$ en la contratación pública o dispensación de ayudas públicas, etcétera, las cuales, en algunas opiniones, habría aún que mejorar y completar ${ }^{23}$.

La institucionalización del deber de abstención implica, en todo caso, una exigencia bastante más amplia que la inherente a las eventuales consecuencias del ejercicio de un derecho de recusación. Lógicamente, este derecho solo se ejercerá en la práctica - y no eran otros los supuestos tradicionales en que podía fundarse - frente a situaciones de las que el recusante pueda temer un daño y no un beneficio, y, además, en cualquier caso, su activación dependerá de la apreciación concreta de personas y circunstancias que hagan los interesados para valorar si deciden recusar en aplicación de alguno de los supuestos que las leyes determinen, o si prefieren que el procedimiento siga adelante aunque pudiese existir alguna de las relaciones contempladas en estos supuestos.

El sentido cautelar, preventivo de la imposición del deber de abstención, refleja probablemente la creciente preocupación de nuestras sociedades por garantizar lo mejor posible el buen comportamiento de las autoridades y de los empleados públicos al servicio de todos, conforme a las exigencias del Estado social y democrático de Derecho, con lo que se busca dificultar la labor de la corrupción en las instituciones públicas, una práctica que tanto daña su eficacia y la confianza pública que sustenta y da solidez a una sociedad. Se trata, incluso, de exigir que los responsables públicos no solo sean buenos — cumplan bien su menester al servicio de todos-, sino que - como suele decirse- lo parezcan. Es decir, que no se encuentren en situaciones que puedan suscitar dudas razonables sobre la corrección de su comportamiento como autoridades o agentes públicos, ni sobre el cumplimiento del principio constitucional de que todos los funcionarios y trabajadores públicos están al servicio de la Nación, como proclama el artículo 39 de la Constitución peruana vigente, de 1993, con cuyos términos pareciera que se comprometen desde el propio presidente de la república hasta a los alcaldes.

22 Véase: SÁnchez Morón, M. Ob. cit., p. 279; y CARRo Fernández-Valmayor, José Luis. Ob. cit., pp.

ÉTICA PÚBLICA Y DEBER DE ABSTENCIÓN EN LA ACTUACIÓN ADMINISTRATIVA

PUBLIC ETHICS AND DUTY OF ABSTENTION IN ADMINISTRATIVE ACTION 


\section{CARÁCTER INCIDENTAL DEL PROCEDIMIENTO DE ABSTENCIÓN Y RECUSACIÓN}

Convendrá advertir que, en todas las regulaciones de la recusación y de la abstención, tanto en el ámbito judicial como en el administrativo, una y otra requieren una decisión — respectivamente, judicial o administrativa - por parte de un órgano superior a aquel del que sea titular la persona en deber de abstención, o del que se fije como competente a tal efecto. Esto hará que el procedimiento correspondiente, aunque sea elemental, tenga siempre un carácter incidental respecto a otro principal, que será el relativo al asunto respecto del que se suscite la cuestión de la abstención o recusación, puesto que el planteamiento de la efectividad del deber de abstención o de una recusación carece de sentido alguno si no es en relación con un asunto concreto sobre el que debe intervenir o decidir la administración o un órgano judicial.

Es lógica la necesidad de este procedimiento incidental y de que su resolución corresponda de ordinario, como decimos, a un superior, pues, en cuanto sea posible, la concurrencia efectiva de la causa que obligue a la abstención —y justifique, en su caso, la recusación — debe ser apreciada lo más objetivamente posible por quien esté en situación enteramente libre de las relaciones de interés, y se encuentre obligado institucionalmente, por algún título organizativo, a velar por el ajuste a Derecho de la actuación de la autoridad o del empleado público del que se trate. Porque tampoco puede admitirse que alguien se acoja sin más o laxamente a un supuesto deber de abstención para soslayar responsabilidades ${ }^{24}$, ni que se utilice por alguno la recusación de forma abusiva o injustificada. Aunque a la vez algún mecanismo de garantía deberá poder impedir que quien sea llamado por el ordenamiento a resolver sobre la abstención de otros pueda utilizarlo para marginar sin causa justificada acreditada a quien, en virtud de la ley, deba intervenir en un procedimiento. Aun sin ser de aplicación al ámbito administrativo algo equivalente a un principio de tanta trascendencia constitucional como el del juez predeterminado por la ley, es claro también que las normas jurídicas de la organización y de la provisión de los diversos empleos públicos, con toda su relevancia en orden al deber - y al derecho- de intervenir o participar de determinada manera en los procedimientos administrativos son de obligado cumplimiento y no admiten manipulaciones interesadas. Más aún, naturalmente, si la autoridad competente para intervenir o decidir, unipersonal o colegiada,

24 El deber de ejercer la función se traduce también en la prohibición de abstención en las votaciones como miembros de órganos colegiados que específicamente se impone a las autoridades y empleados de la administración pública, tanto en el Derecho español (artículo 24.1c de la ley 30/1992), como aún más ampliamente en el peruano (artículo 101 de la ley 27444). Véase: BACA ONETO, V. «Gobierno municipal o administración municipal: la distinción entre las funciones administrativas y las funciones de gobierno en la Ley Orgánica de Municipalidades». XXVIII Congreso Iberoamericano de Municipios, pro manuscripto, p.8. 
debe su designación directa o indirectamente a un mandato confiado por vías democráticas ${ }^{25}$.

Ello nos coloca en definitiva ante determinados actos administrativos —o judiciales, si se trata de ese ámbito- resolutorios de estos incidentes procedimentales —o procesales, en el ámbito judicial—, de los que habrá que predicar el régimen común de los correspondientes actos jurídico-públicos, salvo en lo que la ley diga de específico para ellos ${ }^{26}$.

\section{EL DEBER DE ABSTENCIÓN DE LAS AUTORIDADES ADMINISTRATIVAS EN LA LEY PERUANA DE PROCEDIMIENTO ADMINISTRATIVO GENERAL DE 2001}

La Ley Peruana de Procedimiento Administrativo General de 2001 ha introducido una regulación del deber de abstención en el ámbito administrativo en sus artículos 88 a 94, cuyos rasgos pueden sintetizarse como veremos a continuación: «IV.1. No va acompañado de un tratamiento nominalmente diferenciado de la recusación, pero se reconoce el derecho de los interesados a 'promover' la abstención». Lo primero que llama la atención es la aparente levedad con que la ley de 2001 regula la recusación de la que venimos hablando. No hay referencias a ella con esta denominación ni con ninguna otra similar, y parece ponerse buen cuidado en evitar que pueda considerarse un derecho de los interesados. Se habla, en cambio, de «promoción de la abstención». El artículo 89.2 se limita a disponer en este sentido que «cuando la autoridad no se abstuviera a pesar de existir alguna de las causales expresadas, el administrado puede hacer conocer dicha situación al titular de la entidad, o al pleno, si fuere órgano colegiado, en cualquier momento». Estamos, pues, aparentemente, ante un puro derecho a informar o a denunciar ante el órgano que corresponda de la administración, pero no ante un derecho a exigir que se produzca en efecto la abstención si se verifica que la persona de que se trata está incursa en causal legal ${ }^{27}$, por más que, luego, el artículo 90.1 añada que la orden de abstención pueda producirse a pedido de los administrados, lo que comporta ya algo más que la mera denuncia, pues se contempla una petición.

El tono contrasta, no obstante - al menos a primera vista-, con la regulación de la recusación en el artículo 29 de la ley española 30/1992,

25 Como se ha advertido en la doctrina española. Véase: DOMÉNECH PASCUAL, Gabriel. «La abstención en el procedimiento administrativo". En José María Baño León y Juan Climent Barberá (coordinadores). Nuevas perspectivas del régimen local (estudios en homenaje al profesor José María Boquera Oliver). Valencia: Tirant lo Blanch, 2002, pp. 413-414.

26 Véase: González PÉREZ, Jesús y Francisco González NAVARro. Comentarios a la Ley de Régimen Jurídico de las Administraciones Públicas y Procedimiento Administrativo Común (ley 30/1992, del 26 de noviembre). Cuarta edición. Tomo I. Navarra: Thomson-Civitas, 2007, pp. 885 y siguientes.

27 Así lo entiende expresamente, arguyendo que es algo distinto de la recusación, propia del orden judicial, Juan Carlos Morón Urbina en Nueva Ley del Procedimiento Administrativo General (comentarios). Reimpresión de la primera edición. Lima: Gaceta Jurídica, 2002, p. 238. 
pero hay que reconocer que, sin embargo, no son tantas las diferencias reales. Empleando el mismo término, aun de modo un poco diferente, lo que dice ese precepto de la legislación española es que los interesados pueden promover la recusación en cualquier momento de la tramitación del procedimiento, pero tampoco se reconoce allí, aparentemente, un auténtico derecho exigible mediante tal recusación, y que pudiese ser en consecuencia tutelado por los órganos judiciales. La ley podría dar incluso la impresión de no querer quepa la posibilidad de invocar un interés legítimo, que pudiese tratar de protegerse, al menos directamente, con el derecho a la tutela judicial efectiva garantizado por el artículo 24 de la Constitución. Frente a la resolución de quien deba conocer de la recusación — dice el artículo 29.5 - no cabrá recurso, sin perjuicio de la posibilidad de alegar la recusación al interponer el recurso que proceda contra el acto que termine el procedimiento, lo que podrá servir, sin duda, de posible indicio probatorio relevante, también si el conflicto llega a la vía judicial. Lo mismo, por cierto, que se dispone en el artículo 93 de la ley peruana - aun precisando expresamente que la no impugnabilidad lo es en vía administrativa- Se ha querido, en suma, excluir a la configuración de la recusación en el ámbito administrativo como un auténtico derecho, y hasta como interés legítimo y con derecho a tutela judicial efectiva específica y directa. Más allá, por tanto, de primeras impresiones, la situación de los interesados en un procedimiento, con respecto al cumplimiento del deber de abstención, no es distinta en Perú y en España ${ }^{28}$.

Otra cosa es la cuestión de si constitucionalmente el indudable interés de quien recusa puede ser sustraído a su tutela judicial efectiva. Aunque la ley española no precisa si el recurso que excluye es solo administrativo o también el contencioso-administrativo, toda actuación administrativa, según el artículo 106.1 de la Constitución española, está sujeta al control de los tribunales, y no parece fácil negar que ese interés no tenga, a pesar de todo, la consideración de legítimo, por lo que lo alcanzaría, en consecuencia, el derecho fundamental a la tutela judicial efectiva del artículo 24 del mismo texto constitucional. Ocurre, sin embargo, que ese control judicial no resulta negado enteramente por la legislación, la cual no admite un recurso directo con la resolución sobre la abstención o la recusación, puesto que, en realidad, es posible $-\mathrm{y}$ es de hecho en cierto modo efectuado- con ocasión de la revisión de la legalidad del acto o de la actuación de quien fue objeto de un incidente de abstención o recusación. Bien miradas las cosas, sin embargo, lo que el órgano judicial examinará no es tanto si se incumplió o no el deber de abstención,

28 Lo que explica quizás, por ejemplo, que la directiva 002-2009/TRI-INDECOPI, sobre procedimiento de abstención y recusación, del 14 de mayo de 2009 -obligatoria para todos los funcionarios de los órganos resolutivos de INDECOPI comprendidos en el título V del decreto legislativo 1033, que rige su organización y funciones- asuma sin más y regule la figura de la recusación con su tradicional denominación, en aplicación de las previsiones de la ley 27444 . 
sino si con ello se produjo una ilegalidad invalidante de aquel acto o actuación, que es lo que será el objeto del proceso y en lo que se concentrará la tutela judicial de los derechos e intereses legítimos en juego. De esto resultará que solo podamos hablar de la posibilidad de intereses legítimos sobre la abstención - más que de un propio derecho a ellaen cuanto condicionados, en último extremo y sustantivamente, a la relevancia efectiva de tal abstención para la real acomodación plena del contenido sustantivo del acto o de la actuación administrativa del que se trate, y de su causa legalmente establecida al ordenamiento vigente.

El ordenamiento busca, además, evitar que los incidentes de abstención y recusación interrumpan en exceso los procedimientos —o los procesos, en el orden judicial—, lo que podría abrir la posibilidad de recursos contra las decisiones que los concluyen. Por eso y por el sentido solamente cautelar del deber de abstención, es por lo que se encauza el control de estas decisiones y se lo vincula al control que pueda ejercerse sobre los actos que se adopten en el asunto principal por quien fue objeto de ellas. Así ocurre también en el ámbito judicial ${ }^{29}$. Y es quizás por lo dicho que alguna jurisprudencia española apunte a la condición de acto de trámite de la resolución del incidente de abstención o recusación - que ni impediría la continuidad del procedimiento principal ni produciría por sí mismo indefensión ni perjuicio irreparable-, para justificar su no impugnabilidad ${ }^{30}$, aunque no nos parezca una explicación suficiente ni adecuada, dado que, entre otras cosas, en puridad no se trata en rigor de un trámite, sino de un acto definitivo, resolutorio, de un procedimiento incidental.

Cuestión distinta es que la autoridad o el «servidor público» que sea apartado por quien resuelva el incidente de recusación o de abstención no pueda tener un auténtico derecho al ejercicio de la función, como se ha dicho en la doctrina española, con lo que el caso puede defenderse, obviamente, ante los tribunales, aunque nada diga de específico al respecto la legislación ${ }^{31}$.

En cualquier caso, como se ha observado con razón, del derecho a la recusación —distinto, como hemos dicho, de un derecho a la abstención - se desprende la importancia del derecho a que se notifique a los interesados la identidad de las autoridades y del personal bajo cuya responsabilidad se tramiten y resuelvan los procedimientos que hoy se recogen en el artículo 55.9 de la ley peruana 27444 y en el 35b de la ley 30/1992 española.

ÉTICA PÚBLICA

Y DEBER DE

ABSTENCIÓN EN

LA ACTUACIÓN

ADMINISTRATIVA

PUBLIC ETHICS

AND DUTY OF

ABSTENTION IN

ADMINISTRATIVE

ACTION 


\section{IV.2. Se aplica específicamente a quien tenga la condi- ción de autoridad administrativa, en el sentido con que la legislación administrativa peruana emplea esta expresión}

El artículo 88 dirige el deber de abstención que impone a la autoridad que tenga facultad resolutiva o cuyas opiniones sobre el fondo del procedimiento puedan influir en el sentido de la resolución, en virtud, lógicamente, de una competencia que le esté atribuida.

El artículo 50.2 de la misma ley, para los efectos del cumplimiento de las disposiciones del Derecho administrativo como sujetos del procedimiento, además de los administrados, se considera «autoridad administrativa». Es decir, «el agente de las entidades que bajo cualquier régimen jurídico, y ejerciendo potestades públicas conducen el inicio, la instrucción, la sustanciación, la resolución, la ejecución, o que de otro modo participan en la gestión de los procedimientos administrativos».

En algunos preceptos de la ley se identifica autoridad administrativa con funcionario (artículo 202.2) o con órgano (218.2 y 227.1), y es frecuente hablar de autoridades superiores y jerárquicamente inferiores, o se habla de autoridades instructoras como distintas de las decisorias, aunque hay también preceptos en que se distingue entre autoridades y otro personal al servicio de las mismas entidades administrativas (artículo 238.6, por ejemplo), lo mismo que la rúbrica del capítulo segundo sobre responsabilidad de las autoridades y personal al servicio de la administración pública del que tratan los artículos 239 y siguientes. Y es, en fin, de notar que el mismo artículo 239 se refiere a unas y a otro -independientemente, dice, de su régimen laboral o contractual - como susceptibles de incurrir en falta administrativa en el trámite de los procedimientos administrativos a su cargo, lo que presupone cometidos administrativos de algún relieve que aún no llegan a tener la condición de autoridad.

Parece, en conclusión, que no todo empleado o funcionario público tiene la condición de autoridad administrativa y que, por tanto, el deber de abstención no se aplica a cualquier personal de esa condición. La definición de autoridad que se hace en el artículo 50.2 ofrece algunas dificultades para su interpretación precisa, por venir los verbos conducen y participan en una forma plural, que no permite concordarlos con un sujeto singular como sería la autoridad en cuanto agente, y que, por lo tanto, parece que se refieren a las entidades de que la autoridad es agente. Pero se intuye que lo que se ha querido decir no es lo que literalmente dice, porque si fuese esto, el problema se trasladaría a tratar de acotar lo que quiere decirse cuando se habla de tal agente, ya que todo empleado público podría ser comprendido como tal, lo que no es, sin duda, la idea de esta ley. En cualquier caso, los términos del propio artículo 88 inclinan a pensar que, para reconocerse como autoridad administrativa sujeta al 
deber de abstención, la intervención que pueda tenerse, en virtud de la correspondiente competencia y en el procedimiento de que se trate, ha de comportar alguna capacidad de orientar, influir o determinar, cuando no la de fijar el carácter, momento y contenido del acto o la actuación administrativa de que se trate ${ }^{32}$.

De nuevo aparecen aquí diferencias a primera vista con respecto a la tradicional regulación española desde la Ley de Procedimiento Administrativo de 1958 hasta hoy. Se obligaba con aquella a la abstención (artículo 20) a la autoridad o funcionario que se encontrase en alguna de las causales. Ahora, el artículo 28 de la ley 30/1992 lo hace a las autoridades y el personal al servicio de las Administraciones en quienes concurran las causales. Aparentemente, pues, aunque ni esas dos leyes ni ninguna otra ley administrativa en España defina el significado de autoridades $^{33}$, el deber de abstención en el Derecho administrativo español tendría un ámbito de aplicación subjetivo más amplio que el peruano.

La realidad, sin embargo, no es tan distante, pues también lo decisivo bajo el Derecho español, en la aplicación del deber de abstención, es que el «servidor público» del que se trate — sea autoridad u otro personal- tenga una conexión con un procedimiento abierto «de tal índole» — como se ha, con razón, escrito- «que pueda influir positiva o negativamente en el acto que ponga fin a aquél» ${ }^{34}$.

Lo más probable es que cuando las leyes administrativas españolas hablan de autoridades administrativas quieren referirse a las personas físicas en cuanto titulares de órganos superiores y directivos de las administraciones públicas elegidos o designados por confianza política, comenzando, naturalmente, por los componentes del gobierno nacional o del Estado, los consejos de gobierno de las comunidades autónomas, los ayuntamientos, las diputaciones provinciales o juntas generales vascas y los cabildos insulares. Se contraponen así a todo el personal al servicio de las administraciones públicas, a todo funcionario, contratado

32 Así lo entiende también Juan Carlos Morón Urbina en Ob. cit., p. 233.

33 Sí lo hace el Código penal a sus propios efectos, el cual, actualmente en vigor y aprobado por Ley Orgánica 10/1995, del 23 de noviembre, señala en su artículo 24 que: «1. A los efectos penales se reputará autoridad al que por sí solo o como miembro de alguna corporación, tribunal u órgano colegiado tenga mando o ejerza jurisdicción propia. En todo caso [...] los miembros del Congreso de Diputados, del Senado, de las Asambleas Legislativas de las Comunidades Autónomas y del Parlamento Europeo. Se reputará también autoridad a los funcionarios del Ministerio Fiscal. 2. Se considerará funcionario público todo el que por disposición inmediata de la ley o por elección o por nombramiento de autoridad competente participa en el ejercicio de funciones públicas». Pero estas nociones no son trasladables sin más al Derecho administrativo, puesto que se refieren a los diversos poderes públicos y no solo a las administraciones públicas, y no tienen en cuenta los diversos factores relevantes para el diverso régimen de quienes detentan los gobiernos —incluidos los locales- y sirven a las administraciones por ellos dirigidas. Véase: Luis Rodríguez Ramos (director). Código penal (concordado y comentado). Cuarta edición. Madrid: La Ley, 2011, pp. 290-291.

34 GonZÁlez PÉREZ, Jesús y Francisco GonzÁlez NAVARRO. Ob. cit., p. 871. Ahí, los autores citan como ejemplo de inaplicación del deber de abstención el caso de quien se limita a efectuar una notificación obligatoria (sentencia del 10 de octubre de 1997 de la sala tercera del Tribunal Supremo español). Sigue el mismo criterio Gabriel Doménech Pascual en Ob. cit., p. 414. 
o incluso aquel con otro tipo de vínculos, como los derivados del cumplimiento de una prestación pública obligatoria — miembros de mesas electorales en elecciones generales, autonómicas o locales-. Pero lo que importa, a la postre, es la influencia que, en ejercicio de una propia función o competencia, vaya a poder tenerse en el asunto del que se trate un determinado procedimiento. Y, en este sentido, el resultado no parece que vaya a ser muy distinto del que se desprende de la ley peruana, aunque el alcance de los términos empleados en la legislación administrativa peruana y en la española para denominar los diversos tipos de personas que actúan en nombre de las entidades públicas en cuanto administraciones públicas puedan no coincidir en su alcance semántico, con lo que se daría la impresión al lector español del artículo 88 de la ley peruana que solo están obligados a abstenerse lo que quizás el entienda por autoridades.

\section{IV.3. Se regula como procedimiento incidental sin suspensión del procedimiento principal.}

En efecto, dice el artículo 92 de la Ley del Procedimiento de 2001 que la tramitación de una abstención - y ella, naturalmente, se aplica cuando la promueven los interesados- se realizará en vía incidental, lo que, como ya expusimos, es algo propio de la institución, pero, además, añade este breve precepto que esto se hará sin suspender los plazos para resolver o para que opere el silencio administrativo. En el Derecho español, en cambio, como se recoge ahora en el artículo 77 de la ley 30/1992, aunque «las cuestiones incidentales que se susciten en el procedimiento [en general], incluso las que se refieran a nulidad de actuaciones, no suspenderán la tramitación del mismo». Se exceptúa precisamente, y de modo explícito, la recusación, aunque solo esta y no la abstención, la cual también ha de resolverse, sin embargo, mediante un incidente. Quizás ha pesado en la diferencia de trato de un incidente del otro el diverso papel que juegan en su iniciación los interesados, en cuyo beneficio establecen las normas los plazos para la conclusión de los procedimientos y para el silencio. Con cautelas para evitar el abuso, quizás lo más razonable fuese, con todo, admitir una suspensión, aunque fuese limitada del procedimiento principal.

En cuanto a la tramitación y resolución del incidente, esta regula, ante todo, el artículo 89 de la ley 27444 y su planteamiento por la propia autoridad que se encuentre en alguna de las circunstancias que determinan el deber de abstenerse, dentro de los dos días hábiles siguientes a aquel en que comenzó a conocer del asunto, o en que conoció la causal sobreviniente. Deberá hacerlo en escrito razonado que ha de remitir - parece que con lo actuado, en su caso- al superior jerárquico inmediato, al presidente del órgano colegiado o al pleno, 
según el caso, para que, sin más trámite, se pronuncie sobre la abstención dentro del tercer día.

Esta regulación peruana es más concreta, entra en más detalles — plazos, variedad de tipos de lo que podrían considerarse, o, en una acepción muy amplia, el «superior inmediato»— que la española contenida en el artículo 28 de la ley 30/1992, lo que puede ser plausible. Aunque algún autor ha apuntado una explicación ligada al hecho de que esta ley es lo que en el actual sistema «autonómico» español se conoce como una ley básica — en concreto, que está dirigida a establecer las bases del régimen jurídico de las administraciones públicas que la Constitución reserva al Estado en su artículo 149.1.18 - , por lo que no le correspondería entrar en más pormenores que en el caso de otras leyes estatales o autonómi$\operatorname{cas}^{35}$, la verdad es que el texto procede de la ley de 1958, bajo un sistema estatal bien distinto, aunque también en ese entonces, por razones vinculada al modo de entender la separación de poderes, hubiese quien propugnase que las leyes debían mantenerse en lo básico, dejando el desarrollo al reglamento ${ }^{36}$. La identificación del «superior inmediato» en lo que no se puntualice por otras leyes o reglamentos dentro del Derecho español corresponde a la doctrina y, en último término, a los tribunales. Se ha entendido así, por ejemplo, que de la abstención de un ministro habría de decidir el consejo de ministros ${ }^{37}$, si bien del régimen de la suplencia de los ministros —establecido por el artículo 13 de la ley del gobierno 50/199 - cabría deducir un criterio más bien favorable a que sea el presidente del gobierno el que decida.

Ocurre, con todo, que el artículo 90.1 de la ley peruana dice que el superior jerárquico inmediato ordena, de oficio, o a pedido de los administrados, la abstención del agente incurso en alguna de las causales. Enseguida diremos algo más sobre el supuesto en que actúe a pedido de los administrados — por recusación, en suma-, pero sobre lo que queremos llamar la atención ahora es que se contempla una actuación del superior de oficio. iSe está refiriendo solamente al supuesto en el que es la propia autoridad o el agente que se juzga incurso en causal de abstención quien la plantea conforme a lo dicho en el artículo 89.1? Los términos de oficio se aplicarían entonces, ya que, al fin y al cabo, todo se produce en el seno de la administración, y el acto de la autoridad o del agente que plantea su abstención no hace sino promover la actuación del superior - jerárquico o de otro tipo, aunque, desde luego, inmediato-, pero sin iniciar realmente el procedimiento incidental con una solicitud o instancia formalmente tal.

ÉTICA PÚBLICA
YDEBERDE

ABSTENCIÓN EN

LA ACTUACIÓN

ADMINISTRATIVA

PUBLIC ETHICS

AND DUTY OF

ABSTENTION IN

ADMINISTRATIVE

ACTION 
Pero cabe también entender que el hecho de que se ordene de oficio la abstención comprende también - aunque no se diga nada de esto en los otros preceptos de manera explícita- que el incidente pueda ser incoado directamente por el «superior inmediato», sin planteamiento previo del afectado por el deber de abstención, al que, lógicamente, deberá escucharse en todo caso antes de tomarse la decisión correspondiente. Los procedimientos de oficio incluyen tanto una modalidad como la otra, en principio, y solo suelen oponerse a los que están a instancia de interesado, entendiendo la instancia, en sentido estricto, como solicitud con derecho a resolución. En la ley española 30/1992 se dice, expresamente, queriendo, sin duda, incluir la posibilidad más propia de la actuación de oficio, que los órganos superiores podrán ordenar a las personas en quienes se dé alguna de las circunstancias señaladas a que se abstengan de toda intervención en el expediente. Esto es lo que dispone el apartado 4 del artículo 28, que se viene interpretando en el sentido de que tal orden puede adoptarse por propia iniciativa, incluso en el caso, por tanto, de que el incurso en deber de abstención no lo comunique, y, desde luego - puesto que es algo regulado en el artículo 29-, aunque no mediase recusación. Nos parece que es lo que también quiere decir el precepto peruano.

Por lo que se refiere, en fin, a lo que la tradición y la legislación española denominan recusación, el 89.2 de la ley peruana dispone que, cuando la autoridad no se abstuviera a pesar de existir alguna de las causales expresadas, el administrado puede hacer conocer dicha situación al titular de la entidad, o al pleno, si fuere órgano colegiado, en cualquier momento. Ya nos hemos referido a ello antes y hemos expresado que el artículo 90.1, por su parte, dice que es el superior jerárquico quien puede ordenar en tal caso, a pedido de los administrados, la abstención del agente incurso en algunas de las causales. Las diferencias terminológicas con que están redactados ambos preceptos pueden suscitar dudas respecto a quien puede darse a conocer la situación. Pero, en buena lógica, no podrá ser sino a quien sea competente para resolver el incidente, es decir, según venimos diciendo, el superior inmediato, tanto si lo es por razones propiamente de jerarquía como si lo es por razón de la superioridad que el propio artículo 89.1 parece asignar —al menos a estos efectos-al presidente del órgano colegiado o al pleno de este cuando se trate de miembros de tales órganos colegiados o, quizás, también de órganos dependientes de estos sin vínculo de jerarquía. Eso es lo que, por lo demás, parece desprenderse sin mayor problema del artículo 29 de la ley 30/1992 española, la cual habla de nuevo del «inmediato superior». Nada impediría, con todo, que pudiera expresarse ante la propia persona cuya abstención se promueve —el recusado-, de modo que resulte obligado a paralizar su actuación y a trasladar la recusación al superior inmediato para su resolución, al modo usual en la tradición judicial. 
Lógicamente, cuando el incidente se suscite por recusación presentada por los interesados, será, en cualquier caso, esencial que el superior escuche al recusado. Se trata del principio general jurídico-público de la previa audiencia del interesado en cualquier resolución que pueda afectarle (artículo 105 de la Constitución española, para el ámbito administrativo), pero lo da a entender, además, el artículo 29 de la ley española 30/1992 cuando, en su apartado 3, dice que «en el día siguiente (al que se le comunique la recusación) el recusado manifestará a su inmediato superior si se da o no en él la causa alegada. En el primer caso, el superior podrá acordar su sustitución acto seguido», y añade, en el apartado 4, que «si el recusado niega la causa de recusación, el superior resolverá en el plazo de tres días, previos los informes y comprobaciones que considere oportunos».

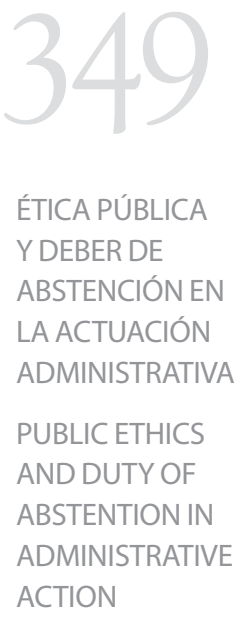

\section{IV.4. Efectos de la orden de abstención}

Dice el artículo 90.2 de la ley 27444 que en el mismo acto en que se ordene la abstención de la autoridad de que se trate se designa a quien continuará conociendo del asunto - preferentemente entre autoridades de igual jerarquía - y le remitirá el expediente.

La regulación española no dice nada explícitamente semejante al ocuparse de la abstención en el artículo 28 de la ley 30/1992, pero sí que se refiere de modo explícito a la sustitución del recusado al tratar de la recusación, en el artículo 29.3, dando a entender que esta sustitución es algo inherente a la resolución que ordene la abstención, dado que, obviamente, las funciones correspondientes no pueden dejar de cumplirse. Esa sustitución, lógicamente, deberá hacerse de conformidad con las reglas que en cada caso sean de aplicación, según el tipo de órgano y de puesto o cargo de que se trate, y se aplicarán de ordinario igualmente en caso de enfermedad, ausencia u otra causa de imposibilidad de actuación del titular del órgano del que se trate, o, incluso, en caso de vacante. Y habrá supuestos en que la sustitución no sea posible o procedente, como en la mayor parte de los órganos colegiados, cuando no se trate de miembros con suplentes o en representación de grupos o entidades que puedan enviar un sustituto para el caso sin incurrir en similar deber de abstención.

La ley peruana añade aún, sin embargo, en el apartado 3 de su artículo 90, que, cuando no hubiere otra autoridad pública apta para conocer del asunto, el superior optará por habilitar a una autoridad ad hoc, o disponer que el incurso en causal de abstención tramite y resuelva el asunto bajo su directa supervisión. Parece que se trata de soluciones que solo podrán aplicarse cuando falten reglas que puedan aplicarse para la sustitución, y que son opciones alternativas que el superior podrá elegir prudencialmente, según aconsejen las circunstancias del asunto. Bajo 
el Derecho español actual, la regulación que hace el artículo 14 de la ley 30/1992 de la figura de la avocación — con laxitud no poco discutible $^{38}$ - permitiría al superior, en efecto, avocar en cualquier caso el conocimiento del asunto.

Nada tiene que ver el hecho de que, una vez debidamente notificada la orden de abstención y la correspondiente sustitución, la persona física de que se trate queda completamente inhabilitada para ejercer válidamente en el caso la función correspondiente, con las consecuencias que puntualizaremos enseguida. No obstante, como añade con buenas razones el artículo 94 de la ley 27444 , la autoridad que por efecto de la abstención sea apartada del procedimiento coopera para contribuir a la celeridad de la atención del procedimiento, sin participar en reuniones posteriores ni en la deliberación de la decisión. De manera que, en efecto, su apartamiento del asunto no solo no impedirá que pueda llevar a cabo alguna actuación en relación con él ni que pueda tener influencia ni efecto condicionante alguno en el sentido de su tratamiento y resolución, sino que, incluso, vendrá obligado a realizarla cuando sea pertinente para la más rápida y segura tramitación del procedimiento.

\section{IV.5.Efectos de la actuación de quien esté incurso en causales de abstención}

La legislación peruana y la española se pronuncian en términos similares en cuanto a este importante extremo de la incidencia de la actuación del incurso en causales de abstención en la validez de lo actuado.

Dice el artículo 91.1 de la ley 27444 que «la participación de la autoridad en el (sic) que concurra cualquiera de las causales de abstención, no implicará necesariamente la invalidez de los actos administrativos en que haya intervenido, salvo en el caso en que resulte evidente la imparcialidad o arbitrariedad manifiesta o que hubiera ocasionado indefensión al administrado».

Por lo que se refiere a la ley española 30/1992, su artículo 28.3 dispone que «la actuación de autoridades y personal al servicio de las Administraciones públicas en los que concurran motivos de abstención no implicará, necesariamente, la invalidez de los actos en que hayan intervenido». Todo lo demás lo da por sentado, puesto que, obviamente, a esos actos se les aplicarán todos los requisitos de validez que son comunes a los actos administrativos, incluidos, por descontado, los relativos a la igualdad de trato y a la no discriminación en la aplicación del ordenamiento, la interdicción de la arbitrariedad, el ajuste a su causa legal sin desviación de poder, etcétera.

38 Véase: DE LOS Mozos TOUYA, Isabel. «La avocación: de la ley de 1958 a la ley 30/1992». Revista Andaluza de Administración Pública, número 22, 1995. 
En definitiva, lo que quiere decirse es que el mero hecho de actuar de manera determinante en un procedimiento administrativo estando incurso en causal de abstención no produce un efecto invalidante de la actuación correspondiente ${ }^{39}$. Es una confirmación de lo que hemos dicho en su momento: el deber de abstención es una medida precautoria, cautelar, pero no una exigencia imprescindible para la legalidad y la consiguiente validez de los actos administrativos o judiciales ${ }^{40}$. Ello no quita, sin embargo, que la actuación — no comunicada al superior- de aquel que está incurso en causal de abstención no comporte una presunción, pero sí un fuerte indicio que puede ser determinante en caso de dudas sobre la imparcialidad u objetividad de lo actuado y provocar así su anulación. No hay por qué, sin embargo, suponer algo así como una presunción de invalidez de lo actuado por el incurso en motivo de abstención, aunque sea iuris tantum, de modo que pueda demostrarse que el acto habría sido el mismo aunque hubiera habido abstención ${ }^{41}$. Siempre ampara al acto administrativo, por el contrario, la presunción de su validez, y siempre habrá que demostrar sus vicios de ilegalidad invalidante para que pueda destruirse tal presunción, declararse la invalidez y anularse, en consecuencia, lo actuado.

Debe advertirse, sin embargo, que los preceptos citados no serían de aplicación al caso de actuación del incurso en deber de abstención una vez le sea notificada debidamente la resolución del superior ordenándole esa abstención y sustituyéndole por otra persona para esa actuación. En ese caso, estaríamos ya ante una actuación claramente ilegal e inválida, e incluso probablemente nula de pleno derecho bajo el Derecho español por falta absoluta de competencia, al haber sido apartada esa persona de la posibilidad de su ejercicio en el caso, lo que, incluso, podría hacer entrar la conducta en alguno de los tipos delictivos relativos a la usurpación de funciones públicas, lo que haría aún más grave el ilícito. Aunque ese fuese el único vicio de ilegalidad de lo actuado, bastaría para su invalidez, sin duda alguna. Hay que entender, pues, que lo dispuesto en el artículo 91 de la ley peruana o en el 28.3 de la ley española 30/1992 solo se aplica a las actuaciones de quienes estén incursos en causal de abstención sin reconocimiento y declaración formal de ello con anterioridad a tales actuaciones. Lo que, por cierto, vendría a justificar el efecto suspensivo que vimos se reconoce a la recusación en Derecho español, porque así se impide que se produzca válidamente la actuación del recusado hasta que se resuelva el incidente.

39 Por excepción establecida expresamente por el artículo 76 de la ley $7 / 1985$, reguladora de las bases del régimen local en España, la actuación de los miembros de las corporaciones locales (ayuntamientos, diputaciones provinciales, cabildos insulares) incursos en motivos de abstención, «implicará, cuando haya sido determinante, la invalidez de los actos en que hayan intervenido».

40 Contra lo afirmado por Doménech Pascual, no parece que estemos ante vicio alguno de forma, ni siquiera ante una mera irregularidad procedimental no invalidante. Se trata de otra cosa, y tiene por eso otro régimen.

41 Contra lo dicho por González Navarro en Ob. cit., p. 888.

ÉTICA PÚBLICA

Y DEBER DE

ABSTENCIÓN EN

LA ACTUACIÓN

ADMINISTRATIVA

PUBLIC ETHICS

AND DUTY OF

ABSTENTION IN

ADMINISTRATIVE

ACTION 


\section{IV.6. Responsabilidad de quien actúa estando incurso en causal de abstención}

La ausencia de efecto de suyo invalidante de la actuación del incurso en causal de abstención no declarada formalmente no impide que de ella puedan derivarse responsabilidades para el que la lleva a cabo, que hay que entender podrán ser, obviamente, más graves, si tal actuación se llevase a cabo con incumplimiento además de la orden superior de abstención. También las legislaciones peruana y española se pronuncian sobre ello análogamente, aunque con más determinación la primera. Dice, en efecto, el artículo 91.2 de la ley peruana de procedimiento, que «el superior jerárquico [- habrá que entender que, en su caso, se refiere a cualquier otro superior al que le corresponda-] dispone el inicio de las acciones de responsabilidad administrativa, civil o penal contra la autoridad que no se hubiese abstenido de intervenir, conociendo la existencia de la causal». Más lacónicamente, el artículo 28.5 de la ley española tanta veces citada dirá que «la no abstención en los casos en que proceda dará lugar a responsabilidad», sin más concreciones y sin el tono tan concretamente imperativo de la ley peruana.

Por responsabilidad administrativa probablemente quiere indicar el texto peruano la disciplinaria que podrá, en su caso, exigirse al personal que, aun actuando como autoridad, en el sentido de la ley peruana, esté sometido a esta potestad como empleado público, en los términos del artículo 239.6 de la misma ley 27444. Así puede ocurrir también en el Derecho español con los funcionarios públicos, e incluso con otros empleados públicos bajo contrato, en cuanto que, como dijimos, actuar incurso en causa de abstención - hacerlo culpablemente, y, por lo tanto, con suficiente evidencia de que se era consciente de elloconstituye falta grave. No parece exigible, en cambio, a las autoridades propiamente políticas, sin perjuicio de las responsabilidades políticas que les puedan ser exigibles.

En el Derecho español no hay una penalización del simple hecho de actuar estando incurso en la administración en deber de abstención. No creo que tampoco exista en el Derecho peruano, sin perjuicio de que en uno y otro derechos pueda incurrirse en figuras delictivas si esa actuación, como ya hemos dicho, se produce tras ser apartado del procedimiento por el superior, con la consiguiente orden formal de abstención, o sin perjuicio también, naturalmente, de que, como consecuencia de la no abstención - aun sin haberse declarado el deber de abstenerse en el caso- se incurra en figuras delictivas como la prevaricación, etcétera.

En fin, por lo que se refiere a la responsabilidad civil o patrimonial por los daños que pueda producir a terceros la actuación de quien está incurso en abstención, habrá que hacer referencia a las reglas establecidas sobre la responsabilidad en este orden de las autoridades y personal al 
servicio de la administración por razón de la actuación de esta, las cuales suelen exigir, además de la efectividad del daño, la concurrencia de dolo, culpa o negligencia graves en el incumplimiento del Derecho que lo haya generado, tal y como se desprende del artículo 145 de la Ley española 30/1992, y más sucintamente del artículo 238.6 de la ley peruana 27444 , ya que esta ley parece contemplar otros supuestos o vías de exigibilidad de la llamada responsabilidad civil, cerrados hoy en el Derecho español — salvo en cuanto a la derivada de delito — para evitar duplicidades —en particular jurisdiccionales—, dada la existencia en España de distintas jurisdicciones ordinarias especializadas junto a la civil, a la laboral y a la contencioso-administrativa ${ }^{42}$.

\section{IV.7. Las causales de abstención y la cuestión de su numerus clausus}

El artículo 88 de la ley 27444, bajo la denominación de causales de abstención, determina, aparentemente de modo taxativo, los casos o supuestos en los que la autoridad sobre la que ya hemos visto que recae este deber debe abstenerse de participar en los asuntos cuya competencia le esté atribuida:

1. Si es pariente dentro del cuarto grado de consanguinidad o segundo de afinidad, con cualquiera de los administrados o con sus representantes, mandatarios, con los administradores de sus empresas, o con quienes les presten servicios.

2. Si ha tenido intervención como asesor, perito o testigo en el mismo procedimiento, o si como autoridad hubiere manifestado previamente su parecer sobre el mismo, de modo que pudiera entenderse que se ha pronunciado sobre el asunto, salvo la rectificación de errores o la decisión del recurso de reconsideración.

3. Si personalmente, o bien su cónyuge o algún pariente dentro del cuarto grado de consanguinidad o segundo de afinidad, tuviere interés en el asunto de que se trate o en otro semejante, cuya resolución pueda influir en la situación de aquél.

4. Cuando tuviese amistad íntima, enemistad manifiesta o conflicto de intereses objetivo con cualquiera de los administrados intervinientes en el procedimiento, que se hagan patentes mediante actitudes o hechos evidentes en el procedimiento.

5. Cuando tuviere o hubiese tenido en los últimos dos años, relación de servicio o de subordinación con cualquiera de los administrados o terceros directamente interesados en el asunto, o si tuviera en proyecto

42 El artículo 2.e de la ley 29/1998, reguladora de la jurisdicción contencioso-administrativa, ha reservado a esta todas las reclamaciones de responsabilidad patrimonial de la administración, cauce obligado para exigir esa responsabilidad a sus autoridades y personal, conforme al artículo 145 de la ley 30/1992. 
una concertación de negocios con alguna de las partes, aun cuando no se concrete posteriormente.

Es notable la similitud con los motivos de abstención especificados en el artículo 28.2 de la ley española 30/1992, aunque son de destacar las diferencias que se explicarán a continuación.

Para comenzar, el texto español puntualiza algo más el alcance de la relación de parentesco relevante, y donde el texto peruano alude a quienes les presten servicios, el español detalla a «asesores, representantes legales o mandatarios que intervengan en el procedimiento» (letra $b$ ).

Por otro lado, el texto español ha añadido a la relación de parentesco otra particular causa de abstención que, aunque tratada en el mismo párrafo, nada tiene que ver con ella, pues se refiere a la circunstancia de «compartir con [los asesores, representantes legales o mandatarios que intervengan en el procedimiento] despacho profesional o estar asociado con éstos para el asesoramiento, la representación o el mandato» (letra b), lo que más parece entrar en los supuestos de incompatibilidad que en los de deber de abstención.

Asimismo, la ley española es más parca en la circunstancia a que se refiere la causal 2 del listado peruano, pues la letra d de su artículo 28.2 se limita a la de «haber tenido intervención como perito o como testigo en el procedimiento de que se trate» y no recoge ni la intervención como asesor ni lo relativo a que "como autoridad hubiere manifestado previamente su parecer sobre el mismo, de modo que pudiera entenderse que se ha pronunciado sobre el asunto» ${ }^{43}$, lo que puede tener particular relevancia en cuanto a la necesidad de separar instrucción y decisión, que, por lo demás, es algo que la ley española tiene establecido ahora imperativamente con respecto en concreto a los procedimientos sancionadores (artículo 134.2), lo mismo que la ley peruana 27444 en su artículo 234.1, aunque este lo condicione a que la organización de la entidad lo permita.

Además, presenta particulares diferencias en una y otra legislación la causal de amistad íntima o enemistad manifiesta con los interesados o sus representantes, asesores mandatarios que intervengan en el procedimiento, porque la ley peruana añade el conflicto de intereses objetivo, y, sobre todo, porque requiere que tales circunstancias «se hagan

43 Por cierto que este motivo de abstención no debiera extenderse al hecho de que se hubieran expresado opiniones relacionadas genérica o específicamente con el asunto al margen del ejercicio de funciones públicas, en medios académicos, doctrinales o de comunicación pública, a título particular, y sin relación personal alguna con el asunto, su gestación o su gestión, que pudieran implicar la posibilidad de algún condicionamiento en su expresión de sentido favorable o adverso, con contrapartidas económicas, profesionales o de cualquier tipo de promoción personal evidenciable. No tendría sentido condicionar la libertad de expresión y científica con la imposición de deberes de abstención en actuaciones públicas en las que haya que aplicar criterios sostenidos o criticados personalmente al margen de ellas y desde otras posiciones desinteresadas en la sociedad. 
patentes mediante actitudes o hechos evidentes en el procedimiento», lo que constituye un interesante acotamiento de supuestos tan difíciles de apreciar. Es a esto último a lo que se ciñe en realidad la diferencia - ciertamente, no pequeña-, porque la letra a del artículo 28.2 de la ley española - lejos, pues, de la letra c en que se trata de la amistad íntima o enemistad manifiesta - ha incluido también expresamente la circunstancia de «tener cuestión litigiosa pendiente con algún interesado», que es algo parecido a lo del conflicto de intereses objetivo, aunque de alcance más reducido y verificable ${ }^{44}$. La ubicación, sin embargo, de este tipo de situaciones parece mejor hecha en la ley peruana.

En el número 5 del listado del precepto peruano de causales, aparece en primer lugar la circunstancia de relación de servicios en los dos últimos años, en términos que, aunque no exactamente los mismos, vienen a tener un alcance semejante a los usados por la letra e del listado de motivos de abstención de la ley española, pero, a la vez, se añade otro que no está en esta y que es interesante, y es «que se tuviera en proyecto una concertación de negocios con alguna de las partes, aun cuando no se concrete posteriormente».

Finalmente, las dos normativas contienen un supuesto de alcance más indeterminado y omnicomprensivo —de mucho más difícil determinación en lo concreto, por tanto-, que presenta también algunas diferencias en cuanto a su formulación textual. El artículo 88 de la ley peruana lo sitúa a mitad de su listado, con el número 3, y el artículo 28.2 de la ley española en el primer lugar del suyo, como letra a. La diferencia principal entre los dos textos es que la ley peruana equipara al «interés personal» en el asunto por parte de la autoridad o empleado público de que se trate, el que puedan tener su cónyuge o algún pariente dentro del cuarto grado de consanguinidad o segundo de afinidad. A pesar de la apariencia ampliatoria del supuesto, en realidad no habrá mucha diferencia, pues si se mencionan estos intereses de los parientes próximos en la ley peruana es porque se considera que esos intereses son compartidos por la autoridad o por el empleado público del que se trate, para el cual no dejarán de ser, por tanto, intereses personales, aunque indirectos.

La ley española se refiere, en cambio, por su parte, en este mismo supuesto y de manera específica, al hecho de «ser administrador de sociedad o entidad interesada», además de al ya comentado de «tener cuestión litigiosa pendiente con algún interesado». Lo primero es más bien propio de los supuestos de incompatibilidad, aunque, desde luego, entra también en el «interés personal». De lo segundo ya hemos dicho que encaja mejor junto a la enemistad manifiesta, pero su mención aquí permite 
destacar que el «interés personal» puede tener, por supuesto, tanto un sentido favorable como adverso.

Se ha planteado en la doctrina si los motivos o causales de la abstención con tasados son numerus clausus, o, por el contrario, si se trata solo de una relación ejemplificativa de los supuestos que más fácilmente pueden presentarse, y que no excluyen a otros.

En realidad, al haberse introducido en los listados el supuesto general de «tener interés personal en el asunto de que se trate o en otro en cuya resolución pudiera influir aquel» (artículo 28.2a de la ley española) o de que «personalmente, o bien su cónyuge o algún pariente dentro del cuarto grado de consanguinidad o segundo de afinidad, tuviere interés en el asunto de que se trate o en otro semejante, cuya resolución pueda influir en la situación de aquél» (artículo 88.3 de la peruana), el alto grado de indeterminación de la noción de interés personal propio y directo, o propio e indirecto, a través del interés del pariente próximo, convierte en realidad al listado en algo muy abierto, en el que su carácter tasado puede parecer más aparente que real.

Sin embargo, debe tratarse de interpretar y aplicar esa tan indeterminada previsión del modo más estricto y aun restringido posible, limitándola a lo que pueda comportar una ventaja o desventaja particularizada, acreditable y medible para la autoridad o para el servidor público actuante como tal -0 , en el caso peruano, para sus parientes en los grados que la ley indica-, individualmente considerado, o como parte de un grupo suficientemente especificado por causas distintas de una simple afinidad o proximidad por razón de la coincidencia en ideas religiosas, filosóficas, políticas, jurídicas, económicas, sociales, profesionales, etcétera, o de una común procedencia o situación local, profesional, escolar o de otros aspectos de la trayectoria vital o la que fuese ${ }^{45}$. No es realista pretender que los administradores públicos hayan de ser personas ajenas a cualquier tipo de interés personal en los asuntos que les corresponde resolver si es que tomamos la noción de interés personal en su significación literal, sin restricción alguna. Las propias directrices políticas que dirigen legítimamente las administraciones públicas comportan un tipo determinado de intereses, que podrán vivirse o interiorizarse como personales por quienes se identifiquen con ellos. Lo importante es que la actuación pública se someta en todo y de modo pleno al ordenamiento jurídico, sean cuales sean los intereses personales de quien actúa. En la

45 La jurisprudencia del Tribunal Supremo español excluye la aplicación del interés personal cuando hay una «difusión extraordinaria del interés», o en el caso de determinados «intereses colectivos» (DOMÉNECH PASCUAL, G. Ob. cit., p. 429). Morón Urbina ha advertido en el Perú que la legislación no ha aceptado causales «que permitan el apartamiento de la competencia por motivos tales como el decoro, la delicadeza, o cualquiera otra causal de autoestimación propias del fuero interno de la administración, del mismo modo que no se pueden admitir abstenciones indiscriminadas u orgánicas que involucren a todo un área o sector de una dependencia pública» (Ob. cit., p. 236). 
medida en que, además, el nivel de la autoridad o del servidor público no sea propiamente directivo sino subordinado al nivel propiamente de gobierno, deberá marcarse aún más la profesionalidad que es propia de los niveles más estrictamente administrativos, a los que se debe preservar en su neutralidad respecto a las alternativas políticas que puedan instalarse en los gobiernos, sin perjuicio de su obligación de atenerse a las legítimas directrices que tales gobierno impartan.

Me parece que, tanto la ley peruana como la española, al fin y a la postre, no dejan de tener un planteamiento razonablemente restrictivo de las causas de abstención, que debe mantenerse, a pesar de la laxitud de este motivo del interés personal que quizás debiera llegar a acotarse de modo más preciso. Sí que se trata, por tanto, a pesar de todo, de un numerus clausus de causales, y no ilimitadamente abierto, sin perjuicio de que el listado general contenido en las leyes generales del procedimiento administrativo - tanto peruana como española_ deba completarse con lo que además dispongan al efecto otras leyes complementariamente ${ }^{46}$. Impedir en casos concretos el ejercicio de sus funciones a quien el ordenamiento ha habilitado para ello debe ser algo excepcional. Su fundamento cautelar debe llevar a hacer una aplicación estricta y restringida de los supuestos que justifiquen esa excepción, los cuales deben estar lo más claramente dispuestos en las leyes y, en cualquier caso, deben ser aplicados prudencialmente por los órganos llamados a apreciarlos, ordenando en cada caso la abstención conveniente, evitando maniobras no menos interesadas, así como la paralización indebida de la acción administrativa, la lesión de derechos al cargo o a la participación o intervención en las funciones de la administración o de otros derechos fundamentales ${ }^{47}$.

ÉTICA PÚBLICA YDEBER DE ABSTENCIÓN EN LA ACTUACIÓN ADMINISTRATIVA

PUBLIC ETHICS AND DUTY OF ABSTENTION IN ADMINISTRATIVE ACTION

46 Doménech Pascual sostuvo, en cambio, una posición marcadamente favorable a la tesis del carácter no tasado de los motivos de abstención, aun reconociendo la tendencia jurisprudencial general contraria. Por otro lado, Ochoa ostiene el numerus clausus y la imposibilidad de su interpretación extensiva (OCHOA I MONZÓ, Joseph. «Abstención y recusación». En José Garberí Llobregat (director). El procedimiento administrativo común (comentarios, jurisprudencia, formularios). Tomo I. Valencia: Tirant lo Blanch, 2007, p. 606. En similar sentido, en Perú, Juan Carlos Morón Urbina insiste en el carácter taxativo y de interpretación restrictivas de las causales en Ob. cit., pp. 233-236. Ocurre, por cierto, lo mismo en el Derecho de otros países, como, por ejemplo, en Argentina (Véase: MURATORIO, Jorge. «La administración pública como sujeto del procedimiento administrativo: la competencia del órgano». En Juan Carlos Cassagne (director). Procedimiento y proceso administrativo. Buenos Aires: Lexis Nexis, 2005, p. 120.

47 Según cuenta Morón Urbina, estas consideraciones habrían sido tenidas en cuenta por la comisión que elaboró el proyecto de la ley 27444 de 2001, para «mantener como regla la estabilidad de la competencia administrativa, y evitar a la vez, que la figura de la abstención pueda ser empleada con otros fines que los perseguidos al contemplarla» (Ob. cit., p. 236). 